\title{
Soy product consumption in 10 European countries: the European Prospective Investigation into Cancer and Nutrition (EPIC) study
}

\author{
L Keinan-Boker ${ }^{1} *$, PHM Peeters ${ }^{1}$, AA Mulligan ${ }^{2}, \mathrm{C} \mathrm{Navarro}^{3}, \mathrm{~N} \mathrm{Slimani}^{4}$ and the EPIC \\ Study Group on Soy Consumption: I Mattisson ${ }^{5}$, E Lundin ${ }^{6}$, A McTaggart $^{2}$, NE Allen ${ }^{7}$, \\ $\mathrm{K}$ Overvad ${ }^{8}$, A Tiønneland ${ }^{9}$, F Clavel-Chapelon ${ }^{10}$, J Linseisen ${ }^{11}$, M Haftenberger ${ }^{12}$,

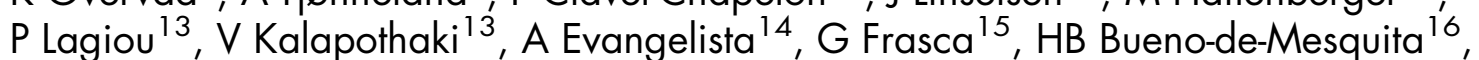
YT van der Schouw ${ }^{1}$, D Engeset ${ }^{17}, \mathrm{G} \mathrm{Skeie}^{17}, \mathrm{~W} \mathrm{Tormo}^{3}, \mathrm{E} \mathrm{Ardanaz}^{18}$, UR Charrondière ${ }^{4}$ and E Riboli ${ }^{4}$

'Julius Center for General Practice and Patient Oriented Research, DO1.335, University Medical Centre Utrecht (UMCU), PO Box 85500, 3508 GA Utrecht, The Netherlands: ${ }^{2}$ Department of Public Health and Primary Care, School of Clinical Medicine, University of Cambridge, UK: ${ }^{3}$ Department of Epidemiology, Regional Health Council, Murcia, Spain: ${ }^{4}$ International Agency for Research on Cancer, Lyon, France: ${ }^{5}$ Department of Medicine, Surgery and Orthopaedics, Lund University, Malmö, Sweden: ${ }^{6}$ Medical Bio-sciences/Pathology and Public Health and Clinical Medicine/Nutritional Research, University of Umeå, Sweden: ${ }^{7}$ Cancer Research UK, Oxford, UK: ${ }^{8}$ Department of Epidemiology and Social Medicine, Aarhus University, Denmark: ${ }^{9}$ Institute of Cancer Epidemiology, Danish Cancer Society, Copenhagen, Denmark: ${ }^{10}$ INSERM, E3N-EPIC Group, Institute Gustave Roussy, Villejuif, France: ${ }^{1}$ Division of Clinical Epidemiology, German Cancer Research Centre, Heidelberg, Germany: ${ }^{2}$ Department of Epidemiology, German Institute of Human Nutrition, Potsdam-Rehbrücke, Germany: ${ }^{13}$ Department of Hygiene and Epidemiology, School of Medicine, University of Athens, Greece: ${ }^{14}$ Unit of Epidemiology, National Cancer Institute, Milan, Italy: ${ }^{15}$ Cancer Registry, 'Civile - M. P. Arezzo' Hospital, Ragusa, Italy: ${ }^{16}$ Cancer Epidemiology, Centre of Chronic Diseases Epidemiology, National Institute of Public Health and the Environment, Bilthoven, The Netherlands:

${ }^{17}$ Institute of Community Medicine, University of Troms $\varnothing$, Norway: ${ }^{18}$ Cancer Registry of Navarra, Institute of Public Health, Regional Government of Navarra, Spain

\begin{abstract}
Objective: The aim of this study was to describe the variation of soy product intake in 10 European countries by using a standardised reference dietary method. A subsidiary aim was to characterise the pattern of soy consumption among a sub-group of participants with a habitual health-conscious lifestyle (HHL), i.e. non-meat eaters who are fish eaters, vegetarians and vegans.

Design: A 24-hour dietary recall interview (24-HDR) was conducted among a sample $(5-12 \%)$ of all cohorts $(n=36900)$ in the European Prospective Investigation into Cancer and Nutrition (EPIC). Study participants totalled 35955 after exclusion of subjects younger than 35 or older than 74 years of age. Soy products were subdivided into seven sub-groups by similarity. Distribution of consumption and crude and adjusted means of intake were computed per soy product group across countries. Intake of soy products was also investigated among participants with an HHL.

Results: In total, 195 men and 486 women reported consuming soy products in the 24-HDR interview. Although soy product intake was generally low across all countries, the highest intake level was observed in the UK, due to over-sampling of a large number of participants with an HHL. The most frequently consumed soy foods were dairy substitutes in the UK and France and beans and sprouts among midEuropean countries. For both genders, the sub-group of soy dairy substitutes was consumed in the highest quantities $\left(1.2 \mathrm{~g} \mathrm{day}^{-1}\right.$ for men; $1.9 \mathrm{~g} \mathrm{day}^{-1}$ for women). Participants with an HHL differed substantially from others with regard to demographic, anthropometric and nutritional factors. They consumed higher quantities of almost all soy product groups.

Conclusions: Consumption of soy products is low in centres in Western Europe. Soy dairy substitutes are most frequently consumed. Participants with an HHL form a distinct sub-group with higher consumptions of fruit, vegetables, legumes, cereals and soy products compared with the other participants.
\end{abstract}

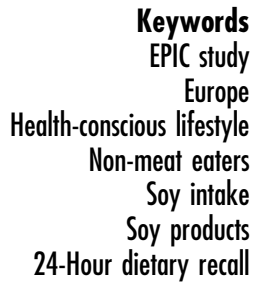


Many studies have suggested that soy has possible beneficial effects on health, due to its phyto-oestrogen content. Isoflavones, mostly genistein and daidzein, are the most notable types of phyto-oestrogen occurring in soy. Structurally they resemble endogenous oestrogen, and have demonstrated both oestrogenic and antioestrogenic properties, as well as antioxidative, antiproliferative and anti-angiogenic activities that are nonhormonally dependent, in many in vitro and in vivo studies $^{1-6}$.

The information on current intake of soy and isoflavones is limited, especially in Western populations. Daily intake of isoflavones is estimated to be between 0.5 and $3 \mathrm{mg} \mathrm{day}^{-1}$ in the $\mathrm{USA}^{7,8}$ and less than $1 \mathrm{mg} \mathrm{day}^{-1}$ in four countries in Europe ${ }^{9,10}$. Many Asian populations consume $20-80 \mathrm{mg} \mathrm{day}^{-1}$ of genistein, which is largely derived from traditional soy foods. It has been reported that Chinese women in Shanghai have a median intake of $100.6 \mathrm{~g} \mathrm{day}^{-1}$ for soy foods, $8.7 \mathrm{~g} \mathrm{day}^{-1}$ for soy protein and $39.6 \mathrm{mg} \mathrm{day}^{-1}$ for isoflavones, as measured by a foodfrequency questionnaire ${ }^{11}$; thus the intake is 13 to 80 times higher than in the USA, The Netherlands, Ireland, Italy or the $\mathrm{UK}^{7-10}$.

Epidemiological studies suggest that consumption of a diet rich in phyto-oestrogens, as seen in traditional Asian societies, is associated with a lower risk of the so-called Western diseases ${ }^{12-15}$ such as coronary heart disease ${ }^{16,17}$, osteoporosis $^{18-20}$, menopausal symptoms ${ }^{21}$ and hormone-dependent cancers such as cancers of the breast, ovary, prostate and colon ${ }^{12,13,22,23}$. Indeed, per capita cereal and phyto-oestrogen consumptions show a negative correlation with mortality rates for these cancers between countries ${ }^{22,24}$.

The aim of this paper is to describe the variation in consumption of soy products in the 10 European countries participating in the European Prospective Investigation into Cancer and Nutrition (EPIC), using a standardised reference dietary method. A subsidiary aim is to characterise and describe soy intake among subjects who are non-meat eaters and who are leading a habitual health-conscious lifestyle (HHL).

\section{Methods and materials}

The rationale of EPIC was to generate prospective, largescale data retrieved from populations that vary widely with regard to both dietary patterns and cancer incidence, in order to investigate diet-cancer associations ${ }^{25}$. The study, which is based in 23 administrative centres in 10 Western European countries (Denmark, France, Germany, Greece, Italy, Norway, Spain, Sweden, The Netherlands and the UK), involves 519978 subjects, all of whom have provided questionnaire data ${ }^{26}$.

Habitual dietary intake was assessed using countryspecific methods ${ }^{26}$. Therefore additional, standardised 24-hour diet recall interviews (24-HDR) were performed among a sample of the study subjects and used as a common calibration reference tool in order to adjust for systematic over- or underestimation of individual baseline dietary intake. Samples were selected randomly from each cohort, weighted according to the cumulative numbers of cancer cases expected over a 10-year follow-up period per gender and 5-year age stratum. Thus, they represent between $5 \%$ and $12 \%$ (1.5\% in the UK) of the total EPIC cohort in each participating country, and are referred to as the EPIC calibration study population ${ }^{27-30}(n=36900)$. A detailed description of the rationale for the EPIC calibration study, its design and the characteristics of the study population are given elsewhere in this supplement $^{31}$. A software program (EPIC-SOFT) was developed for this purpose by the International Agency for Research on Cancer in collaboration with all EPIC centres. The structure and functions of EPIC-SOFT are described in detail elsewhere ${ }^{32,33}$, as are the general concepts and preliminary results ${ }^{34}$.

The soy product study is based on the EPIC calibration study. The number of study participants following exclusion of subjects younger than 35 or older than 74 years of age totalled 35955 and included 13031 (36.2\%) men and 22924 (63.8\%) women. In France, Norway, Utrecht (The Netherlands) and Naples (Italy), only women were recruited into EPIC.

All 24-HDR interviews included questions regarding habitual diet and eating patterns and therefore enabled the classification of participants as meat eaters or meat avoiders. For the Oxford cohort only it was possible to further characterise the meat avoiders as fish eaters, vegetarians or vegans by using replies to a question independent from the 24-HDR. Participants who habitually avoid consumption of meat were subsequently defined as leading a habitual health-conscious lifestyle (HHL). The calibration study population included 412 participants with an HHL, of whom 136 (33.0\%) were men and $276(67.0 \%)$ were women. Two hundred and nineteen (53.0\%) of the participants with an HHL originated from the UK, as this cohort selectively recruited a large number of non-meat eaters to obtain a wide range of dietary intake. Subsequently, the UK EPIC calibration population was regrouped into two sub-groups unrelated to their original geographical study centres (Cambridge and Oxford): the cohort of subjects recruited from the general population via general practitioners in both study centres, which is referred to as the general population group ( $n=$ $975)$, and the 'health-conscious' group $(n=311)$, which was mainly recruited by post and included mostly subjects with an HHL, but also 92 meat eaters who were excluded from all further analyses concerning participants with an HHL.

Various soy products were reported in the 24-HDRs from each of the 10 countries participating. No standardised food composition tables were available to estimate the soy content of each soy product, so they were 
classified by similarity into seven product groups: (1) beans and sprouts; (2) dairy substitutes (75\% are liquid items: milk, cream, drinks; and 25\% are solid items: cheese, yoghurt, desserts and ice creams); (3) grain products (bread, pasta, flour, flakes); (4) meat substitutes (soy schnitzels, hamburgers, frankfurters, soy balls and mixed foods); (5) spreads and pastes; (6) traditional foods (miso, tofu, tempeh); and (7) non-specified foods (when reporters were unable to specify the type of soy food consumed). The soy sauces and the soy oil and margarine groups were excluded, as these products do not contain isoflavones and their contribution to the total soy consumption is rather low. All results are presented separately for men and women. The distribution of soy product consumption is described by country. In order to describe the levels of soy food consumption across countries, we examined the distribution curves and computed the sample medians and the sample means and their standard errors. Crude and adjusted means of consumption $\left(\mathrm{g} \mathrm{day}^{-1}\right)$ per soy sub-group across countries were calculated on the basis of individual intake. Owing to the low number of reporters of soy intake, crude and adjusted means of consumption are presented by country rather than centre, except for the two groups from the UK.

Crude means of consumption were adjusted for age by using linear regression models. Adjusted means were subsequently weighted according to recall season (autumn, winter, spring and summer) and day of the week, in order to compensate for day-to-day and seasonal variations in diets. For this purpose, days of the week were categorised into weekdays (Monday-Thursday) and weekend days (Friday-Sunday). Results for soy product consumption were similar when placing Friday in the weekday category. Crude and adjusted means of intake for those individuals reporting soy consumption in the 24HDR were also computed. Further adjustment for energy intake did not alter the results substantially $(<5 \%$ change) and is not presented here.

A second aim of this study was to describe soy product intake among the sub-group of participants with an HHL, who were hypothesised to consume considerable amounts of soy products. We describe characteristic demographic, anthropometric and nutritional factors for participants with an HHL and the other participants. Computed crude and adjusted means of soy product consumption among participants with an HHL across soy product groups were computed as well.

All analyses were done using the SPSS 9.0 statistical package for Windows ${ }^{35}$.

\section{Results}

Among the 35955 calibration study participants (36\% men and $64 \%$ women), soy products were consumed on 1174 occasions by 681 participants, 342 (29\%) of them occurring among men and 832 (71\%) among women.
Table 1 presents the distribution of consumption of soy products among men and women. In total, 1.5\% of males and $2.1 \%$ of females reported soy consumption in the $24-$ HDR. Among UK 'health-conscious' participants, approximately $35 \%$ of males and $24 \%$ of females reported consumption of soy in the 24-HDR, compared with $1 \%$ of males and $2 \%$ of females among the general population of the UK.

Spain, Greece, Sweden, Denmark and Norway had the lowest proportion of participants reporting soy consumption for both genders (0.2-0.8\%).

Of the seven soy product groups, soy dairy substitutes were consumed the most frequently among both men and women. However, there is a large variation between countries: in The Netherlands, Germany and Spain, the most frequently consumed soy food group among both genders was beans and sprouts; in Italy, grain products; in Denmark, soy meat substitutes; and in both populations of the UK, soy dairy substitutes (Table 1). In most countries (Italy, Spain, both populations of the UK, The Netherlands, Germany and Denmark), males and females most frequently consumed the same type of soy food groups.

Distribution curves of all soy food groups were skewed. Medians for all sub-groups were zero for both genders.

Tables 2 and 3 present the crude and adjusted means of soy product intake across countries for men and women, respectively. Soy dairy substitutes were consumed in the highest quantities among men and women, with adjusted means of 1.2 and $1.9 \mathrm{~g} \mathrm{day}^{-1}$, respectively. Men and women of the UK 'health-conscious' group consumed the highest quantities of soy dairy substitutes (149 and $112 \mathrm{~g} \mathrm{day}^{-1}$, respectively), soy meat substitutes (15.9 and $4.7 \mathrm{~g} \mathrm{day}^{-1}$, respectively), soy traditional foods (8.5 and $5.3 \mathrm{~g} \mathrm{day}^{-1}$, respectively) and non-specific soy foods ( 22.3 and $14.4 \mathrm{~g} \mathrm{day}^{-1}$, respectively). However, intake levels for the UK general population were substantially lower; mean intake of soy dairy substitutes was 0.7 and $5.3 \mathrm{~g} \mathrm{day}^{-1}$ for men and women, respectively, and mean intake of soy meat substitutes was 0.4 and $0.2 \mathrm{~g} \mathrm{day}^{-1}$ for men and women, respectively.

Among the 681 participants reporting soy intake in the 24-HDR interview, the highest intakes were reported for soy dairy substitutes (62.6 and $32.8 \mathrm{~g} \mathrm{day}^{-1}$ for men and women, respectively), while soy grain products were consumed in the lowest quantities among men $\left(2.8 \mathrm{~g} \mathrm{day}^{-1}\right)$ and soy pastes and spreads among women $\left(0.3 \mathrm{~g} \mathrm{day}^{-1}\right)$ (Tables 2 and 3$)$.

Table 4 presents the general characteristics of the subgroup of participants with an HHL and the rest of the cohort. Four hundred and twelve subjects were following an HHL, of which 136 (33.0\%) were men and 276 (67.0\%) were women. As indicated before, due to the oversampling of non-meat eaters in the UK 'health-conscious' group, $71 \%$ of men and $50 \%$ of women with an HHL originated from the UK.

Men and women with an HHL were more educated, 
Table 1 Distribution of soy product consumption among the European Prospective Investigation into Cancer and Nutrition (EPIC) calibration study population: men and women

\begin{tabular}{|c|c|c|}
\hline Country $(n)$ & $\begin{array}{l}\text { Number of individuals reporting } \\
\text { soy consumption (\% of total) }\end{array}$ & $\begin{array}{l}\text { Soy product group consumed } \\
\text { most frequently }\end{array}$ \\
\hline \multicolumn{3}{|l|}{ Greece } \\
\hline M (1312) & $5(0.4)$ & Soy meat substitutes \\
\hline $\mathrm{F}(1374)$ & $11(0.8)$ & Soy dairy substitutes \\
\hline \multicolumn{3}{|l|}{ Spain } \\
\hline M (1777) & $7(0.4)$ & Soy beans and sprouts \\
\hline$F(1443)$ & $6(0.4)$ & Soy beans and sprouts \\
\hline \multicolumn{3}{|r|}{ 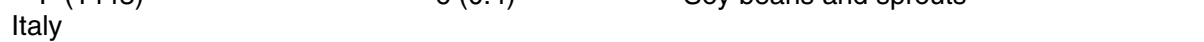 } \\
\hline M (1444) & $24(1.7)$ & Soy beans and sprouts, soy grain products \\
\hline$F(2512)$ & $52(2.1)$ & Soy grain products \\
\hline \multicolumn{3}{|l|}{ France } \\
\hline M (0) & NA & - \\
\hline$F(4639)$ & $150(3.2)$ & Soy dairy substitutes \\
\hline \multicolumn{3}{|l|}{ Germany } \\
\hline M (2268) & $33(1.5)$ & Soy beans and sprouts \\
\hline $\mathrm{F}(2150)$ & $37(1.7)$ & Soy beans and sprouts \\
\hline \multicolumn{3}{|l|}{ The Netherlands } \\
\hline M (1024) & $61(6.0)$ & Soy beans and sprouts \\
\hline$F(2960)$ & $125(4.2)$ & Soy beans and sprouts \\
\hline \multicolumn{3}{|c|}{ UK, general population } \\
\hline M (404) & $3(0.7)$ & Soy dairy substitutes \\
\hline $\mathrm{F}(571)$ & $11(1.9)$ & Soy dairy substitutes \\
\hline \multicolumn{3}{|l|}{ UK, 'health-conscious' } \\
\hline$M(114)$ & $40(35.1)$ & Soy dairy substitutes \\
\hline $\mathrm{F}(197)$ & $47(23.8)$ & Soy dairy substitutes \\
\hline \multicolumn{3}{|l|}{ Denmark } \\
\hline M (1923) & $12(0.6)$ & Soy meat substitutes \\
\hline $\mathrm{F}(1995)$ & $21(1.1)$ & Soy meat substitutes \\
\hline \multicolumn{3}{|l|}{ Sweden } \\
\hline M (2765) & $10(0.4)$ & Soy grain products \\
\hline$F(3285)$ & $23(0.7)$ & Soy dairy substitutes \\
\hline \multicolumn{3}{|l|}{ Norway } \\
\hline$M(0)$ & NA & - \\
\hline$F(1798)$ & $4(0.2)$ & Soy dairy substitutes \\
\hline \multicolumn{3}{|l|}{ Total } \\
\hline$M(13031)$ & $195(1.5)$ & Soy dairy substitutes \\
\hline $\mathrm{F}(22924)$ & $486(2.1)$ & Soy dairy substitutes \\
\hline Total: $M+F(35955)$ & $681(1.9)$ & Soy dairy substitutes \\
\hline
\end{tabular}

$\mathrm{M}$ - male; F - female; NA - not available.

younger, taller, had a lower body mass index (BMI) and were less likely to be current smokers than the others (Table 4). Mean total energy intake $\left(\mathrm{kcal} \mathrm{day}^{-1}\right)$ was lower for men with an HHL, but not for women. Both men and women with an HHL consumed a lower percentage of their daily energy intake as protein and fat and a higher percentage of their daily energy intake as carbohydrates than the rest of the cohort. Participants with an HHL also had higher intakes of fruit, vegetables, legumes, cereals and cereal products and non-alcoholic beverages, and lower intakes of dairy products, eggs and egg products, fish and shellfish and alcoholic beverages, than the rest of the cohort (Table 4).

Table 5 presents the crude and adjusted means of soy product intake among participants with an HHL and the rest of the cohort. Male participants with an HHL did not consume soy beans and sprouts, and consumed a considerably smaller quantity of soy grain products than the others, but they did consume considerably higher amounts of all other soy product groups compared with the rest of the cohort (excluding non-specific soy foods).
In particular, the intake of soy dairy substitutes was high, with a mean intake of $106.5 \mathrm{~g} \mathrm{day}^{-1}$ among male participants with an HHL compared with $0.3 \mathrm{gday}^{-1}$ among the rest of the cohort (Table 5).

Women with an HHL consumed all soy product groups in larger amounts than the rest of the cohort (excluding non-specific soy foods). As for men, the highest intake of soy among women with an HHL was for dairy substitutes (70.8 $\mathrm{g} \mathrm{day}^{-1}$ compared with $1.2 \mathrm{~g} \mathrm{day}^{-1}$ for the rest of the cohort). The lowest intake of soy products among women with an HHL was for soy grain products $\left(0.2 \mathrm{~g} \mathrm{day}^{-1}\right)$ (Table 5).

\section{Discussion}

Soy foods have been a staple part of the Chinese diet for more than 4000 years but have only become more popular in Western countries over the last few decades. The results of this study indicate a low, but variable intake of soy products across Western European countries.

Soy intake varied across Europe, with the most common 


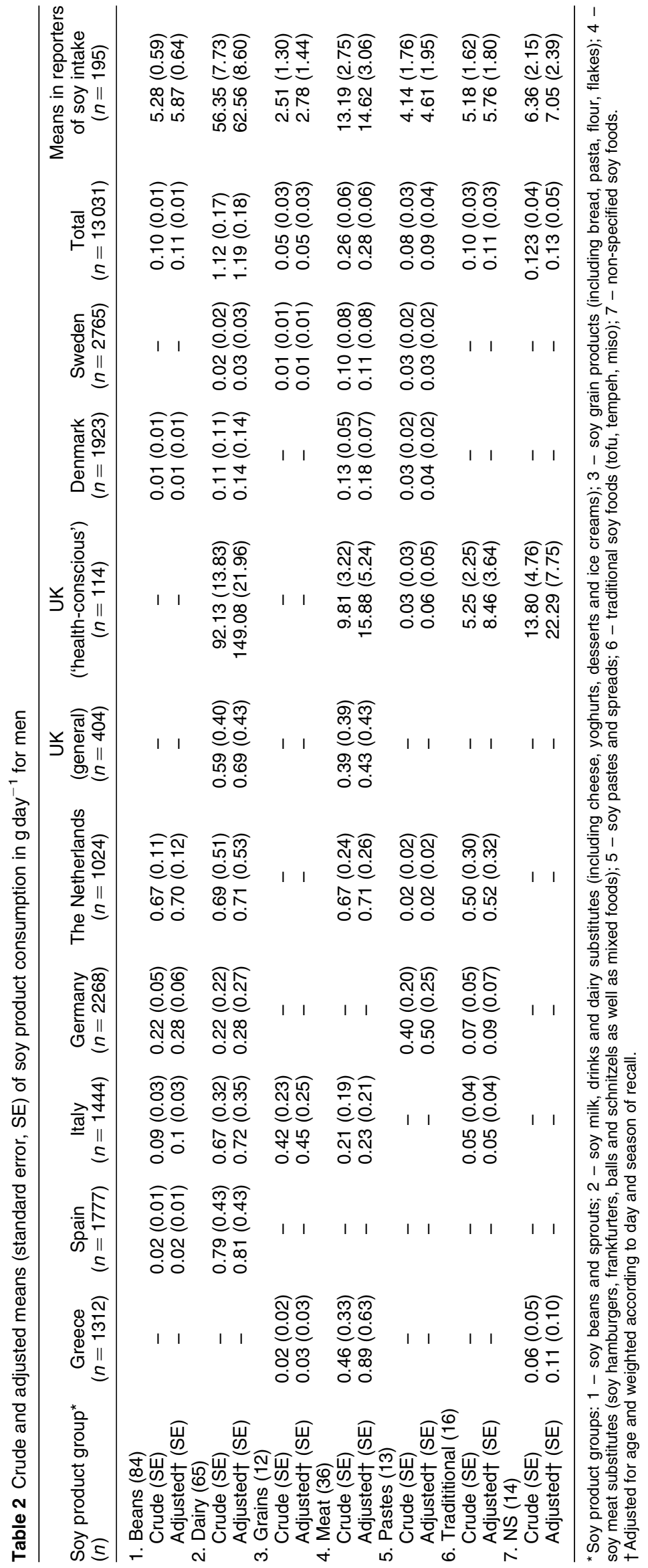


Table 4 Characteristics of subjects with a habitual health-conscious lifestyle (HHL; non-meat eaters), compared with other subjects

\begin{tabular}{|c|c|c|c|c|}
\hline \multirow[b]{2}{*}{ Variable } & \multicolumn{2}{|c|}{ Men } & \multicolumn{2}{|c|}{ Women } \\
\hline & $\begin{array}{l}\text { Participants } \\
\text { with an HHL }\end{array}$ & $\begin{array}{l}\text { Rest of } \\
\text { the cohort }\end{array}$ & $\begin{array}{l}\text { Participants } \\
\text { with an HHL }\end{array}$ & $\begin{array}{l}\text { Rest of } \\
\text { the cohort }\end{array}$ \\
\hline$n$ & 136 & 12895 & 276 & 22648 \\
\hline Current smokers (\%) & 13.4 & 27.9 & 8.1 & 18.5 \\
\hline Academic education (\%) & 49.3 & 21.4 & 41.7 & 20.9 \\
\hline Mean age in years (SD) & $54.6(7.4)$ & $56.8(8.0)$ & $52.9(8.2)$ & $55.3(8.0)$ \\
\hline Mean height in $\mathrm{cm}$ (SD) & $177.1(7.1)$ & $174.2(7.4)$ & $164.2(6.2)$ & $162.3(6.6)$ \\
\hline Mean weight in $\mathrm{kg}$ (SD) & $73.4(9.9)$ & $81.8(11.8)$ & $62.6(10.4)$ & $67.0(11.7)$ \\
\hline Mean BMl in $\mathrm{kg} \mathrm{m}^{-2}$ (SD) & $23.4(2.9)$ & $27.0(3.5)$ & $23.2(4.0)$ & $25.5(4.4)$ \\
\hline Mean energy intake in kcal day ${ }^{-1}$ (SD) & $2216.0(762.7)$ & $2533.3(872.0)$ & $1888.1(679.1)$ & $1874.7(637.2)$ \\
\hline$\%$ of daily energy from carbohydrate (\%) & 52.2 & 42.2 & 51.2 & 45.2 \\
\hline$\%$ of daily energy from protein $(\%)$ & 11.8 & 14.7 & 12.2 & 15.5 \\
\hline$\%$ of daily energy from fat (\%) & 34.2 & 37.1 & 34.7 & 36.4 \\
\hline Mean intake of fruit in g day ${ }^{-1}(\mathrm{SD})$ & $282.3(264.1)$ & $220.4(251.6)$ & $284.5(240.6)$ & $226.4(215.2)$ \\
\hline Mean intake of vegetables in g day $^{-1}$ (SD) & $249.9(200.4)$ & $169.5(162.1)$ & $235.4(172.9)$ & 167.9 (149.2) \\
\hline Mean intake of legumes in $\mathrm{g} \mathrm{day}^{-1}$ (SD) & $34.0(108.7)$ & $14.5(57.4)$ & $15.3(46.1)$ & $7.1(34.1)$ \\
\hline Mean intake of dairy products in g day ${ }^{-1}$ (SD) & $196.8(264.7)$ & $298.6(289.1)$ & $244.5(307.3)$ & $289.1(241.6)$ \\
\hline Mean intake of eggs and egg products in $\mathrm{g} \mathrm{day}^{-1}$ (SD) & $7.3(21.4)$ & $17.4(35.7)$ & $5.4(16.0)$ & $13.7(29.0)$ \\
\hline Mean intake of cereals and cereal products in $\mathrm{g} \mathrm{day}^{-1^{\prime}}(\mathrm{SD})$ & $283.6(203.0)$ & $246.8(172.7)$ & $199.9(139.2)$ & $170.3(118.6)$ \\
\hline Mean intake of fish and shellfish in $\mathrm{g} \mathrm{day}^{-1}$ (SD) & $7.6(37.8)$ & $42.9(86.4)$ & $13.3(40.4)$ & $31.2(64.7)$ \\
\hline Mean intake of non-alcoholic beverages in g day $^{-1}$ (SD) & $1585.2(852.4)$ & $1320.9(866.3)$ & $1665.5(864.9)$ & $1435.6(832.2)$ \\
\hline Mean intake of alcoholic beverages in g day $^{-1}$ (SD) & $204.0(438.5)$ & $366.1(510.7)$ & $89.6(196.7)$ & $117.6(211.2)$ \\
\hline
\end{tabular}

SD - standard deviation; BMI - body mass index.

soy products being beans and sprouts, grain products and dairy substitutes in Mediterranean countries (Spain, France, Italy and Greece). Soy beans and sprouts are the most commonly consumed soy products in mid-European countries (The Netherlands and Germany), while soy meat substitutes are most frequently consumed in Denmark. Soy dairy substitutes are most commonly consumed in France and the UK.

Quantification of direct soy intake in our study population was not feasible, as we had no valid data regarding the soy content of each relevant food item across participating countries. However, this study suggests that the consumption of all soy products is low across Europe, at least among those not following a health-conscious diet. Dietary recall questionnaires have been used to estimate the intake of isoflavones among Japanese $^{36}$ and Korean ${ }^{37}$ subjects, by applying a phytooestrogen value found in the literature per soy item studied. Using this approach, median intakes have been reported to be between 9 and $12 \mathrm{mg} \mathrm{day}^{-1}$ for daidzein and 15 and $20 \mathrm{mg} \mathrm{day}^{-1}$ for genistein in $\operatorname{Japan}^{36}$, and total isoflavone intake has been estimated to be about

Table 5 Consumption of soy products in g day $^{-1}$ by participants with a habitual health-conscious lifestyle (HHL), compared with other subjects

\begin{tabular}{|c|c|c|c|c|c|}
\hline \multirow[b]{2}{*}{ Soy product groups ${ }^{*}$} & \multirow[b]{2}{*}{ Mean } & \multicolumn{2}{|c|}{ Men } & \multicolumn{2}{|c|}{ Women } \\
\hline & & $\begin{array}{c}\text { Participants } \\
\text { with an HHL }(n=136)\end{array}$ & $\begin{array}{l}\text { Rest of the cohort } \\
\quad(n=12895)\end{array}$ & $\begin{array}{c}\text { Participants } \\
\text { with an } \mathrm{HHL}(n=276)\end{array}$ & $\begin{array}{l}\text { Rest of the cohort } \\
\qquad(n=22648)\end{array}$ \\
\hline \multirow[t]{2}{*}{ 1. Beans and sprouts } & Crude (SE) & - & $0.11(0.01)$ & $0.54(0.31)$ & $0.20(0.03)$ \\
\hline & Adjusted† (SE) & & $0.11(0.01)$ & $0.67(0.38)$ & $0.21(0.03)$ \\
\hline \multirow[t]{2}{*}{ 2. Dairy substitutes } & Crude (SE) & 77.34 (11.83) & $0.32(0.09)$ & $57.42(8.67)$ & $1.13(0.13)$ \\
\hline & Adjusted † (SE) & $106.50(16.18)$ & $0.34(0.10)$ & $70.80(10.70)$ & $1.21(0.14)$ \\
\hline \multirow[t]{2}{*}{ 3. Grain products } & Crude (SE) & $<0.01(<0.01)$ & $0.05(0.03)$ & $0.16(0.16)$ & $0.10(0.02)$ \\
\hline & Adjusted† (SE) & $<0.01(0.01)$ & $0.05(0.03)$ & $0.20(0.20)$ & $0.10(0.02)$ \\
\hline \multirow[t]{2}{*}{ 4. Meat substitutes } & Crude (SE) & $8.84(2.77)$ & $0.17(0.05)$ & $4.44(1.26)$ & $0.11(0.02)$ \\
\hline & Adjusted $\dagger$ (SE) & $12.17(3.83)$ & 0.18 & $5.47(1.55)$ & $0.12(0.029)$ \\
\hline \multirow[t]{2}{*}{ 5. Soy pastes } & Crude (SE) & $1.06(0.67)$ & $0.07(0.03)$ & $0.25(0.14)$ & $0.01(<0.01)$ \\
\hline & Adjusted† (SE) & $1.46(0.92)$ & 0.08 & $0.31(0.17)$ & $0.01(0.01)$ \\
\hline \multirow[t]{2}{*}{ 6. Traditional foods } & Crude (SE) & $5.62(2.07)$ & $0.04(0.02)$ & $2.65(0.87)$ & $0.06(0.02)$ \\
\hline & Adjusted $†$ (SE) & $7.75(2.86)$ & 0.05 & $3.30(2.79)$ & 0.06 (0.02) \\
\hline \multirow[t]{2}{*}{ 7. Non-specified } & Crude (SE) & 11.56 (4.01) & $<0.01(<0.01)$ & $6.84(2.26)$ & $<0.01(<0.01)$ \\
\hline & Adjusted† (SE) & $15.92(5.55)$ & $<0.01$ & 8.46 & $<0.01(<0.01)$ \\
\hline
\end{tabular}

SE - standard error.

* Soy product groups: 1 - soy beans and sprouts; 2 - soy milk, drinks and dairy substitutes (including cheese, yoghurts, desserts and ice creams); 3 - soy grain products (including bread, pasta, flour, flakes); 4 - soy meat substitutes (soy hamburgers, frankfurters, balls and schnitzels as well as mixed foods); 5 - soy pastes and spreads; 6 - traditional soy foods (tofu, tempeh, miso); 7 - non-specified soy foods.

† Adjusted for age and weighted according to day and season of recall. 
Table 6 Mean levels of isoflavones in selected food items, expressed in $\mathrm{mg} / 100 \mathrm{~g}$ of edible portion ${ }^{38}$

\begin{tabular}{|c|c|}
\hline Food item & Total isoflavones* \\
\hline \multicolumn{2}{|l|}{ Beans and sprouts } \\
\hline Soy beans & $84.0(13.8-153.4)$ \\
\hline \multicolumn{2}{|l|}{ Soy dairy substitutes } \\
\hline Soy milk & $9.6(1.26-21.1)$ \\
\hline Soy cheese (unspecified) & $31.3(3.33-21.1)$ \\
\hline Cheddar & $7.1(3.40-10.9)$ \\
\hline Mozzarella & 7.7 (based on one sample) \\
\hline Parmesan & 6.4 (based on one sample) \\
\hline Soy yoghurt & 16.3 (based on one sample) \\
\hline \multicolumn{2}{|l|}{ Soy meat substitutes } \\
\hline $\begin{array}{l}\text { Soy hot dog, bacon, } \\
\text { chicken nuggets, burger }\end{array}$ & $12.0(9.0-15.1)$ \\
\hline \multicolumn{2}{|l|}{ Soy paste } \\
\hline Soy paste & $31.5(3.31-59.4)$ \\
\hline \multicolumn{2}{|l|}{ Soy traditional foods } \\
\hline Tofu & $39.0(22.63-67.49)$ \\
\hline Tempeh & $43.5(6.88-62.5)$ \\
\hline Miso & $42.6(23.0-89.0)$ \\
\hline $\begin{array}{l}\text { Natto (boiled and fermented } \\
\text { soybeans) }\end{array}$ & $58.9(46.4-87.0)$ \\
\hline
\end{tabular}

${ }^{*}$ Genistein, daidzein, glycetin.

$15 \mathrm{mg} \mathrm{day}^{-1}$ in Korea ${ }^{37}$ and about $40 \mathrm{mg} \mathrm{day}^{-1}$ in China ${ }^{11}$. In our study, daily intakes of isoflavones were estimated based on isoflavone values of soy foods, listed in Table $6^{38}$, which have been published in the literature. Excluding participants from the UK 'health-conscious' group, mean estimates for daily isoflavone intake for both genders were lower than $2.0 \mathrm{mg} \mathrm{day}^{-1}$. These estimates are in line with previously published data concerning Western populations $^{7-10}$.

Not only are the quantities of intake of soy products among Western subjects substantially lower than among Asian subjects, the sources of soy foods differ as well. Our findings indicate that soy dairy substitutes are the soy foods most frequently consumed and in the highest quantities, while traditional soy products are being consumed at less than $1 \mathrm{~g} \mathrm{day}^{-1}$. This is in stark contrast with Japanese, Chinese and Korean individuals, whose estimated intake of traditional soy products has been reported to be about $100 \mathrm{~g}$ daily ${ }^{11,36,37,39,40}$. Such a low level of consumption may complicate the detection of significant associations between exposure and end results in future analytical studies. However, significant associations between isoflavone dietary intake and risk for prostate cancer $^{41}$ or chronic heart diseases ${ }^{42}$ were reported previously in Caucasian populations consuming a Western diet, with a low intake of soy. Low as it is, the soy intake in the calibration study population might be underestimated, as soy protein has long been utilised in food systems (whole soybeans processed into snack foods, beverages and fermented foods; soy flour and grits blended into corn, wheat or sorghum and used in cereal mixtures or baked goods; soy proteins used in processed meat products or added to soup stock cubes and doughnuts). Obviously, exposure to unsuspected and hidden sources of soy is generally unaccounted for ${ }^{43-45}$.

For UK 'health-conscious' participants and participants with an HHL, the mean consumption of almost all soy product groups was substantially higher than for the rest of the cohort and the estimated daily isoflavone intake was in the range of $15-30 \mathrm{mg} \mathrm{day}^{-1}$, comparable with levels of consumption in Asian diets ${ }^{11,37,38}$. These estimates have been confirmed by Verkasalo et $a l^{46}$, who showed that high soy consumers in EPIC-Oxford had average isoflavone intakes and serum isoflavone concentrations similar to those of Asian populations. This means that although soy dairy substitutes and soy meat substitutes contain smaller quantities of isoflavones than traditional soy foods such as tofu, miso and natto per $100 \mathrm{~g}$ of edible food item (Table 6$)^{38}$, the total daily intake of isoflavones may be comparable. This is most likely due to different portion sizes and a higher frequency of consumption of soy dairy substitutes than traditional soy products.

In addition to a higher soy intake among participants with an HHL, this sub-group also differed from the other participants with regard to age and certain anthropometric (mean BMI), nutritional (percentage of energy produced from carbohydrates) and dietary (intakes of fruit, vegetables, cereals and legumes) factors, which is consistent with other data on vegetarians and vegans ${ }^{47-50}$. Thus, a high consumption of soy products among Western subjects may be a marker of a healthier habitual lifestyle. This sub-group could therefore serve as a reference group in future analytical studies in which various hypotheses on the association between the intake of certain food groups (i.e. meat or isoflavones) and diseases might be tested.

This study is the first to describe the consumption of soy products in Western Europe, in which soy intake is based mostly on easily accessible and ready-to-eat products, and thus different from traditional soy products consumed by Asian populations. Its main advantage is the coverage of a variety of national, geographical and cultural regions. However, in order to evaluate the study findings, one should consider several methodological issues. Although the study population is sampled from, and representative of, the different EPIC cohorts, it is not, in itself, a representative sample on the national level. In addition, lack of standardisation of the different soy items across the participating countries (soy content, ingredients) has limited our ability to estimate direct soy and isoflavone intakes. It may be argued that use of the 24-HDR is prone to day-to-day variations in food intake, especially when less frequently consumed foods, such as soy, are concerned. This would have created a problem if we were to describe individual habitual daily intake of soy. However, we aimed to describe the variability of soy intake between countries. As the calibration study included a random sample of each of the EPIC cohorts and as the sampling procedures were distributed on all seasons and days of the week ${ }^{31}$, it is reasonable to expect 
that the population mean will not be influenced by day-today variability of individual intake. A question may arise regarding the appropriateness of using the population mean, not its median, when distribution curves are skewed. Indeed, geometric means or medians are sometimes preferred to the means when one plans to report statistical tests or, perhaps, when there is a special interest in the centre of a distribution, i.e. when focus is on the socalled typical individual in a population. However, the property that the sample mean is an unbiased estimator of the population mean, regardless of the underlying distribution of the variable, justifies the use of a mean when the aim is focused on population, not individual, intake, as is the case in this study.

An additional point refers to the range of intake; Asian populations generally present with uniformly high soy consumption, while intake in Western populations is obviously uniformly low (except for the sub-group of nonmeat eaters). The uniform range of consumption levels, either in the high or the low soy-consuming societies, may mask possible associations between exposure and endpoints.

As soy intake is currently being studied world-wide with regard to its possible associations with many chronic diseases, improvement of the information on soy intake in Europe is of great importance. Likewise, use of populations with a wide range of soy consumption for analytical studies may prove to be more informative and useful.

\section{Acknowledgements}

The work described in this paper was carried out with financial support of the 'Europe Against Cancer' Programme of the European Commission (SANCO); Ligue contre le Cancer (France); Société $3 \mathrm{M}$ (France); Mutuelle Générale de l'Education Nationale; Institut National de la Santé et de la Recherche Médicale (INSERM); Institute Gustave Roussy; German Cancer Aid; German Cancer Research Centre; German Federal Ministry of Education and Research; Danish Cancer Society; Health Research Fund (FIS) of the Spanish Ministry of Health; the Spanish Regional Governments of Andalucia, Asturias, Basque Country, Murcia and Navarra; Cancer Research UK; Medical Research Council, UK; Stroke Association, UK; British Heart Foundation; Department of Health, UK; Food Standards Agency, UK; Wellcome Trust, UK; Greek Ministry of Health; Greek Ministry of Education; Italian Association for Research on Cancer; Italian National Research Council; Dutch Ministry of Public Health, Welfare and Sports; Dutch Prevention Funds; LK Research Funds; Dutch ZON (Zorg Onderzoek Nederland); World Cancer Research Fund; Swedish Cancer Society; Swedish Scientific Council; Regional Government of Skane, Sweden; Norwegian Cancer Society; Norwegian Research Council. Partial support for the publication of this supplement was provided by the Centre de Recherche et d'Information Nutritionnelles (CERIN).

In addition, we wish to thank all study participants for their co-operation and all interviewers who participated in the fieldwork studies in each EPIC centre.

\section{References}

1 Price KR, Fenwick GR. Naturally occurring oestrogens in foods - a review. Food Addit. Contam. 1985; 2: 73-106.

2 Knight DC, Eden J. Phytoestrogens - a short review. Maturitas 1995; 22: 167-75.

3 Mazur W. Phytoestrogen content in foods. Ballières Clin. Endocrin. Metab. 1998; 12: 729-42.

4 Mazur W, Fotsis T, Wahala K, Ojala S, Salakka A, Adlercreutz H. Isotope dilution gas chromatographic-mass spectrometric method for the determination of isoflavonoids, coumestrol, and lignans in food samples. Anal. Biochem. 1996; 233: 169-80.

5 Mazur W, Wahala K, Rasku S, Salakka A, Hase T, Adlercreutz $\mathrm{H}$. Lignan and isoflavonoid concentrations in tea and coffee. Br.J. Nutr. 1998; 79: 37-45.

6 Mazur W, Duke JA, Wahala K, Rasku S, Adlercreutz H. Isoflavonoids and lignans in legumes: nutritional and health aspects in humans. J. Nutr. Biochem. 1998; 9: 193-200.

7 Horn-Ross PL, Lee M, John EM, Koo J. Sources of phytoestrogen exposure among non-Asian women in California, USA. Cancer Causes Control 2000; 11: 299-302.

8 De Kleijn MJJ, van der Schouw YT, Wilson PWF, Adlercreutz $\mathrm{H}$, Mazur W, Grobbee DE, et al. Intake of dietary phytoestrogens is low in postmenopausal women in the United States: the Framingham study (1-4). J. Nutr. 2001; 131: 1826-32.

9 Keinan Boker L, van der Schouw YT, de Kleijn MJJ, Jacques PF, Grobbee DE, Peeters PHM. Intake of dietary phytoestrogens in Dutch women. J. Nutr. 2002; 132: 1319-28.

10 Van Erp-Baart AMJ, Brants HAM, Kiely M, Mulligan A, Turrini $\mathrm{A}$, Sermineta $\mathrm{C}$, et al. Isoflavone intakes in different European countries: the VENUS approach [abstract]. Ann. Nutr. Metab. 2001; 45: 219.

11 Chen Z, Zheng W, Custer LJ, Dai Q, Shu XO, Jin F, et al. Usual dietary consumption of soy foods and its correlation with the excretion rate of isoflavonoids in overnight urine samples among Chinese women in Shanghai. Nutr. Cancer 1999; 33: $82-7$.

12 Adlercreutz H. Western diet and Western diseases: some hormonal and biochemical mechanisms and associations. Scand.J. Clin. Lab. Invest. 1990; 50(Suppl. 201): 3-23.

13 Adlercreutz H, Mazur W. Phyto-oestrogens and Western diseases. Ann. Med. 1997; 29: 95-120.

14 Bingham SA, Atkinson C, Liggins J, Bluck L, Coward A. Phyto-oestrogens: where are we now? Br.J. Nutr. 1998; 79: 393-406.

15 Setchell KD. Phytoestrogens: the biochemistry, physiology, and implications for human health of soy isoflavones. Am. J. Clin. Nutr. 1998; 68(Suppl.): 1333S-46S.

16 Anderson JW, Johnstone BM, Cook-Newell ME. Metaanalysis of the effects of soy protein intake on serum lipids. N. Engl.J. Med. 1995; 333: 276-82.

17 Van der Schouw YT, de Kleijn MJ, Peeters PH, Grobbee DE. Phyto-oestrogens and cardiovascular disease risk. Nutr. Metab. Cardiovasc. Dis. 2000; 10: 154-67.

18 Alekel DL, St Germain A, Peterson CT, Hanson KB, Stewart JW, Toda T. Isoflavone-rich soy protein isolate attenuates bone loss in the lumbar spine of perimenopausal women. Am.J. Clin. Nutr. 2000; 72: 844-52.

19 Horiuchi T, Onouchi T, Takahashi M, Ito H, Orimo H. Effect 
of soy protein on bone metabolism in postmenopausal Japanese women. Osteoporosis Int. 2000; 11: 721-4.

20 Wangen KE, Duncan AM, Merz-Demlow BE, Xu X, Marcus R, Phipps WR, et al. Effect of soy isoflavones on markers of bone turnover in premenopausal and postmenopausal women. J. Clin. Endocrinol. Metab. 2000; 85: 3043-8.

21 Kronenberg F. Hot flashes. In: Lobo RA, ed. Treatment of the Postmenopausal Woman. New York: Raven Press, 1994; 97-116.

22 Messina M, Persky V, Setchell KD, Barnes S. Soy intake and cancer risk: a review of the in vitro and in vivo data. Nutr Cancer 1994; 21: 113-31.

23 Peeters PHM, Keinan Boker L, van der Schouw YT, Grobbee DE. Phytoestrogens and breast cancer risk. Review of the epidemiological evidence. Breast Cancer Treat. Res. 2002; in press.

24 Rose DP, Boyar AP, Wynder EL. International comparisons of mortality rates for cancer of the breast, ovary, prostate and colon, and per capita food consumption. Cancer 1986; 58 : 2363-71.

25 Riboli E. Nutrition and cancer: background and rationale of the European Prospective Investigation into Cancer and Nutrition (EPIC). Ann. Oncol. 1992; 3: 783-91.

26 Riboli E, Hunt KJ, Slimani N, Ferrari P, Norat T, Fahey M, et al. European Prospective Investigation into Cancer and Nutrition (EPIC): study populations and data collection. Public Health Nutr. 2002; 5(6B): 1113-24.

27 Plummer M, Clayton D, Kaaks R. Calibration in multi-centre cohort studies. Int. J. Epidemiol. 1994; 23: 419-26.

28 Kaaks R, Plummer M, Riboli E, Estee J, van Staveren WA Adjustment for bias due to errors in exposure assessments in multi-center cohort studies on diet and cancer: a calibration approach. Am. J. Clin. Nutr. 1994; 59(Suppl.): S245-50.

29 Kaaks R, Riboli E, van Staveren WA. Calibration of dietary intake measurements in prospective cohort studies. Am. J. Epidemiol. 1995; 142: 548-56.

30 Kaaks R, Riboli E. Validation and calibration of dietary intake in measurements in the EPIC project. Int.J. Epidemiol. 1997; 26(Suppl. 1): S15-25.

31 Slimani N, Kaaks R, Ferrari P, Casagrande C, Clavel-Chapelon F, Lotze G, et al. European Prospective Investigation into Cancer and Nutrition (EPIC) calibration study: rationale, design and population characteristics. Public Health Nutr. 2002; 5(6B): $1125-45$.

32 Slimani N, Deharveng G, Charrondière UR, van Kappel AL, Ocké MC, Welch A, et al. Structure of the standardized computerized 24-hour diet recall interview used as reference method in 22 centres participating in the EPIC project. Comput. Meth. Programs Biomed. 1999; 53: 251-66.

33 Voss S, Charrondière UR, Slimani N, Kroke A, Riboli E, Wahrendorf $\mathrm{J}$, et al. EPIC-SOFT a European computer program for 24-hour-dietrary protocols [in German]. Z. Ernabrungswiss. 1998; 37: 227-33.

34 Slimani N, Ferrari P, Ocké M, Welch A, Boeing H, Liere M, et al. Standardisation of the 24-hour diet recall calibration method used in the European Prospective Investigation into
Cancer and Nutrition (EPIC): general concepts and preliminary results. Eur. J. Clin. Nutr. 2000; 54: 900-17.

35 SPSS, Inc. Statistical Package for the Social Sciences, Version 9.0. Chicago, IL: SPSS, Inc., 1998.

36 Wakai K, Egami I, Kato K, Kawamura T, Tamakoshi A, Lin A, et al. Dietary intake and sources of isoflavones among Japanese. Nutr. Cancer 1999; 33: 139-45.

37 Kim J, Kwon C. Estimated dietary isoflavone intake in Korean population based on National Nutrition Survey. Nutr. Res. 2001; 21: 947-53.

38 USDA-Iowa State University Database on the Isoflavone Content of Foods - 1999 [online]. Available at http://www. nalusda.gov/fnic/foodcomp/Data/isoflav/isfl_tbl.pdf.

39 Shu XO, Jin F, Dai Q, Wen W, Potter JD, Kushi LH, et al. Soyfood intake during adolescence and subsequent risk of breast cancer among Chinese women. Cancer Epidemiol. Biomark. Prev. 2001; 10: 483-8.

40 Ho SC, Woo JL, Leung SS, Sham AL, Lam TH, Janus ED Intake of soy products is associated with better plasma lipid profiles in the Hong Kong Chinese population. J. Nutr. 2000; 130: $2590-3$.

41 Strom SS, Yamamura Y, Duphrone CM, Spitz MR, Babaian RJ, Pillow PC, et al. Phytoestrogen intake and prostate cancer: a case control study using a new database. Nutr. Cancer 1999; 33: $20-5$.

42 Goodman-Gruen D, Kritz-Silverstein D. Usual dietary isoflavone intake is associated with cardiovascular disease risk factors in postmenopausal women. J. Nutr. 2001; 13: 1202-6.

43 Bookwalter GN. Soy protein utilization in food systems. Adv. Exp. Med. Biol. 1978; 105: 749-66.

44 Vidal C, Perez-Carral C, Chomon B. Unsuspected sources of soybean exposure. Ann. Allergy Asthma Immunol. 1997; 79 : $350-2$.

45 Meyer R, Chardonnens F, Hubner P, Luthy J. Polymerase chain reaction (PCR) in the quality and safety assurance of food: detection of soya in processed meat products. Z. Lebensm. Unters. Forsch. 1996; 203: 339-44.

46 Verkasalo PK, Appleby PN, Allen NE, Davey G, Adlercreutz $\mathrm{H}$, Key TJ. Soya intake and plasma concentrations of daidzein and genistein: validity of dietary assessment among eighty British women (Oxford arm of the European Prospective Investigation into Cancer and Nutrition). $\mathrm{Br}$. J. Nutr. 2001; 86: 1-8.

47 Key TJ, Davey GK, Appleby PN. Health benefits of a vegetarian diet. Proc. Nutr. Soc. 1999; 58: 271-5.

48 Janelle KC, Bart SI. Nutrient intakes and eating behavior scores of vegetarian and nonvegetarian women. J. Am. Diet. Assoc. 1995; 95: 180-6.

49 Appleby PN, Thorogood M, Mann JI, Key TJA. The Oxford vegetarian study: an overview. Am. J. Clin. Nutr. 1999; 70(Suppl.): 525S-31S.

50 Haddad EH, Berk LS, Kettering JD, Hubbard RW, Peters WR. Dietary intake and biochemical, hematologic and immune status of vegans compared with nonvegetarians. Am.J. Clin. Nutr. 1999; 70(Suppl.): 586S-93S. 